\title{
Prognosis of concomitant users of clopidogrel and proton-pump inhibitors in a high-risk population for upper gastrointestinal bleeding
}

\author{
Qing Wang ${ }^{1}$, Rickard Ljung ${ }^{1,2}$, Jesper Lagergren ${ }^{1,3}$ and Yunxia Lu ${ }^{1,4^{*}}$
}

\begin{abstract}
Background: It is unclear whether concomitant use of clopidogrel and proton-pump inhibitors (PPIs) increases the risk of recurrence of cardiovascular disease or death in patients at high risk of upper gastrointestinal (GI) bleeding.

Methods: Based on the Swedish Patient Register, a cohort of cardiovascular disease (including acute myocardial infarction, stroke and angina, from 2006 to 2008) was selected from a population with any diagnosis of upper $\mathrm{Gl}$ bleeding. Data on drug prescription was retrieved from the Prescribed Drug Register. Patients entered into the cohort after their first discharge for cardiovascular disease and were followed up to death, recurrence of cardiovascular disease, or 90 days. A Cox regression model was conducted and hazard ratios (HRs) with 95\% confidence intervals (Cls) were estimated to evaluate the risks among users of different drug prescriptions.
\end{abstract}

Results: Patients who were current users of only PPIs (HR 2.02, 95\% Cl 1.19-3.44), only clopidogrel (HR 1.14, $95 \% \mathrm{Cl}$ 0.53-2.45) and nonusers of both ( $\mathrm{HR} 2.36,95 \% \mathrm{Cl}$ 1.39-4.00) were at a higher risk of death compared with patients with a concomitant use. Results were similar among 1779 patients who had any history of upper Gl bleeding (HR 2.05, 95\% Cl 1.18-3.54; HR 1.25, 95\% Cl 0.57-2.72; HR 2.30, 95\% Cl 1.33-3.98, respectively).

Conclusion: Among patients at high risk of upper GI bleeding, those with a concomitant use of PPIs and clopidogrel were at a decreased risk of mortality, and possibly also a decreased risk of recurrence of cardiovascular disease.

Keywords: Clopidogrel, Proton-pump inhibitors, Gastrointestinal bleeding, Cardiovascular disease

\section{Background}

Clopidogrel is a widely used medication for atherosclerotic diseases [1], particularly in the prevention of thrombotic events in stable cardiovascular disease, and as a secondary prevention after myocardial infarction and stroke [2,3]. Upper gastrointestinal (GI) bleeding is, however, a common and potentially serious adverse event in clopidogrel users [4]. Proton-pump inhibitors (PPIs), drugs that alleviate acid-related symptoms by inhibition of the hydrogen-potassium adenosine triphosphatase enzyme in gastric mucosa [5,6], are often prescribed to prevent such bleedings [5,7-9]. However,

\footnotetext{
* Correspondence: yunxia.lu@ki.se

'Department of Molecular Medicine and Surgery, Karolinska Institutet, SE-171

76 Stockholm, Sweden

${ }^{4}$ Department of Epidemiology and Biostatistics, Imperial College London,

London, United Kingdom

Full list of author information is available at the end of the article
}

there are reports of an increased risk of mortality and recurrence of cardiovascular disease among patients with concomitant use of clopidogrel and PPIs [10-14]. A possible mechanism is that PPIs, which are mainly metabolized by the cytochrome system, might counteract the inhibitory effect of clopidogrel on platelet aggregation $[15,16]$. Nevertheless, some other studies have failed to find any interaction between clopidogrel and PPIs [17-19], or any increase in the risk of cardiovascular rehospitalizations [20]. There is presently no general consensus on this issue, although the US Food and Drug Administration and the European Medicines Agency have stated that PPIs may reduce the effect of clopidogrel in the prevention of serious cardiovascular events [21,22].

During the past four years, accumulating relevant studies have been published. Few studies, however, have

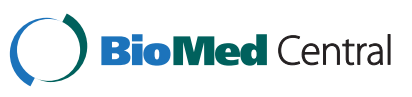


focused on patients with cardiovascular disease at high risk of upper GI bleeding [23]. Most have excluded patients with a history of GI bleeding [14,17,18,20,24] although these patients might be at high risk of a recurrence of severe GI bleeding. Furthermore, these studies have mainly evaluated the combined use of clopidogrel and aspirin together with PPIs which might dilute or mix the real interaction between clopidogrel and PPIs $[25,26]$. In addition, recurrence of cardiovascular disease is the major measured outcome in most previous studies rather than death. Death, though, is the most important and clearly measured outcome for cardiovascular disease and acute peptic ulcer bleeding. The recurrence of cardiovascular disease is, however, generally difficult to be identified completely.

In this cohort study, we focused on cardiovascular disease with any diagnosis of upper GI bleeding to clarify whether concomitant use of clopidogrel and PPIs increases the risk of recurrence of cardiovascular disease or death, compared with other treatment strategies.

\section{Methods}

\section{Study design}

Within a population-based cohort of patients (1987 to 2008 in Sweden) with any hospitalization for complicated upper GI ulcer disease (International Classification of Disease 10th revision [ICD] diagnosis codes: K25-K28 with 0.0 . 1.4 .6 ), patients were selected for the final study if they had been hospitalized for cardiovascular disease from 2006 until the end of 2008. The entry date into the study cohort was the discharge date of the first cardiovascular disease hospitalization after January 1, 2006 (Figure 1). Patients were followed for 60, 90, 180 and
360 days to assess the outcomes death, re-hospitalization, or revisit to outpatient/primary health care for cardiovascular disease. In this study, we only present the results of the 90-day follow-up. The reason for this is that the shortterm drug prescriptions after discharge for cardiovascular disease might more appropriately reflect the treatment in relation to fatality and recurrence. Moreover, restriction of the follow-up to only 60 days, 180 days and 360 days after entry rendered similar results to the 90-day follow-up (data not shown).

\section{Data sources}

Data regarding basic patient information (admission date, discharge date, main diagnosis and secondary diagnosis) were retrieved from the Swedish Patient Register, which has been completed nationwide since 1987. Information on prescribed drugs and dates of dispatch were retrieved from the similarly complete Swedish Prescribed Drug Register (SPDR), which was initiated in July 1, 2005. This register contains information on age, sex, personal number, prescriber's profession and practice and, particularly, drug utilization and expenditure on prescribed drugs for the entire Swedish population. The defined cohort began on January 1, 2006, in order to ensure drug exposure covering at least half a year. The legally compulsory register of prescribed drugs in Sweden guarantees the complete capture of drugs exposure in this study. Death dates and underlying causes of death were identified from the nationwide complete Swedish Cause of Death Register (initiated in 1952), and data on cancer as a co-morbidity was collected from the nationwide complete Swedish Cancer Register (initiated in 1958).

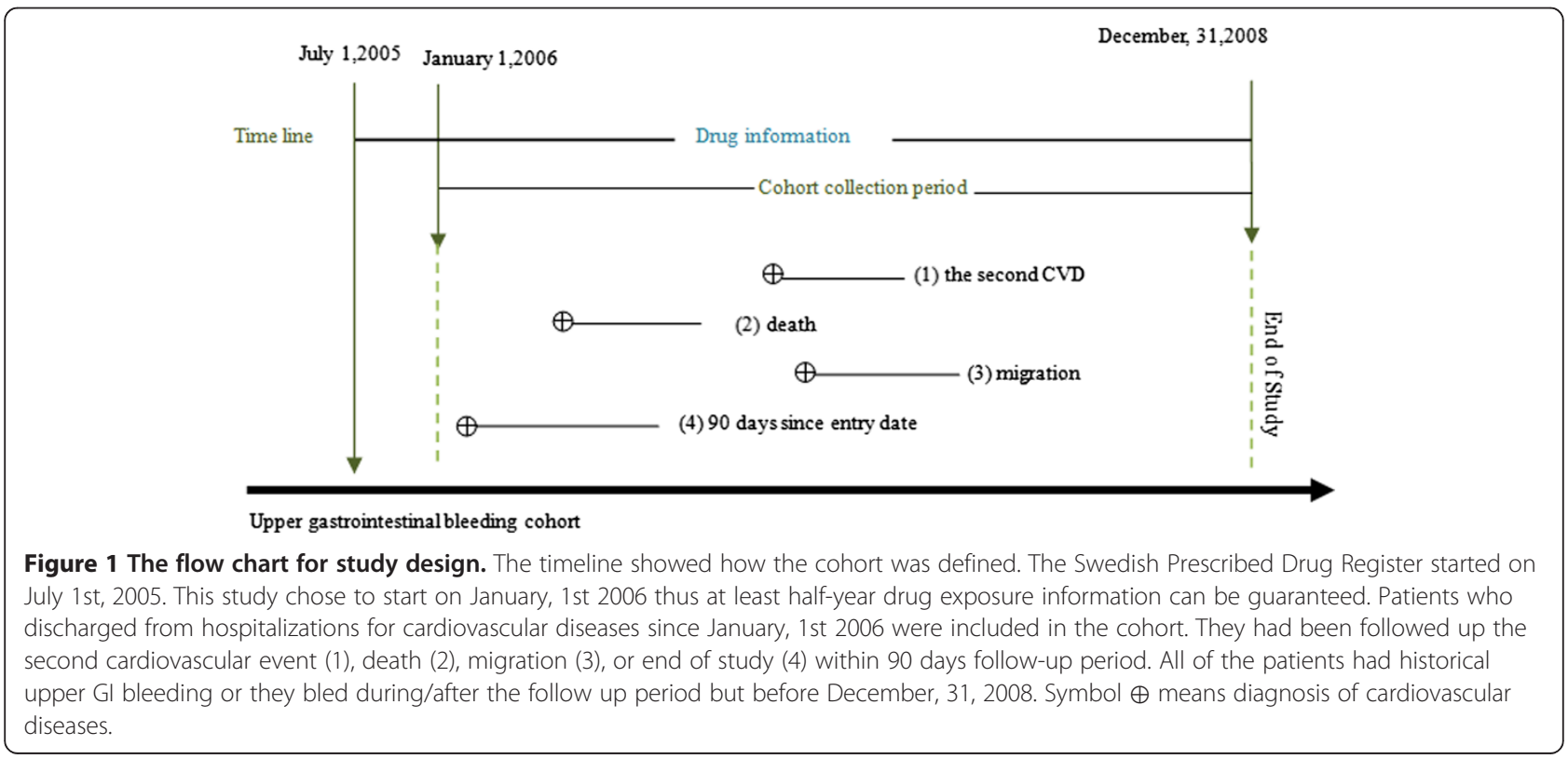




\section{Identification of the study cohort}

As we described above in the Study design section, patients with a first hospitalization for cardiovascular disease (including acute myocardial infarction, stroke, and angina) after January 1, 2006, were included in the study. These diseases were identified from the following ICD codes: main diagnosis or co-diagnosis of acute myocardial infarction (I21, I22), main diagnosis or co-diagnosis of ischemic stroke (I63, I64), and main diagnosis of angina (I20). In order to focus on clopidogrel and PPIs, we excluded patients with any filled prescription of aspirin (Anatomical Therapeutic Chemical [ATC] code: B01AC06, N02BA01, A01AD05) during the study period. Patients were also excluded from the final study cohort if they had previous acute myocardial infarction, stroke or angina hospitalizations within one year before entry, if they had emigrated before January 1, 2006, or if they had a cardiovascular rehospitalization or had died less than 7 days after entry.

\section{Drug exposures}

Current drug use was categorized into four groups: i) only PPIs, ii) only clopidogrel, iii) both clopidogrel and PPIs and, iv) no PPIs or clopidogrel. All the PPI types available in Sweden were included (omeprazole, pantoprazole, lansoprazole, rabeprazole, esomeprazole). The sample size did not allow separate analyses of single PPI groups. We calculated drug exposures at 30 days before the entry date as some patients might have had leftovers of previous PPIs or clopidogrel prescriptions at hand, which might have met their demands for current medications. We also analyzed the data using drug exposure that started from the entry date, or drug exposure 60 days before the entry. All of the results based on three definitions of exposures were similar. Thus, to make the study more concise, we only used the first definition of drug exposure. In Sweden, the typical prescription for PPIs or clopidogrel is for approximately 90 days or less. The extra 30 days plus 90 days of follow-up ensured enough time to cover any defined drug exposures. The ATC codes for clopidogrel were B01AC04 and B01AC30, and the ATC codes for PPIs were A02BC01-05 and A02BD01-06.

\section{Definition of outcomes}

The outcomes under study were: recurrence of acute myocardial infarction (main or secondary diagnosis codes I21 or I22), stroke (main or secondary diagnosis codes I60-I64), angina (main diagnosis code I20), or allcause mortality. We also specified hemorrhagic stroke and ischemic stroke from the total stroke patients.

\section{Co-morbidities}

A co-morbidity score was calculated based on the following concomitant diagnoses: $i$ ) chronic heart failure (diagnosis code I50); ii) diabetes (diagnosis codes E10E14); iii) chronic liver insufficiency (diagnosis codes K702K704, K709, K717, K72, or K743-K746); iv) chronic renal insufficiency (diagnosis codes N18, N19, I132, I200, or I311); v) chronic obstructive lung disease (diagnosis codes J42-J44); vi) malignancy (diagnosis codes C00-C97). The reason for the selection of these diseases for the calculation of the co-morbidity score is because they are very commonly diagnosed and are composed of the most frequent causes of death in an elderly population [27,28]. The number of co-morbidities was categorized into four groups: no concomitant diagnosis, one concomitant diagnosis, two concomitant diagnoses, three or more concomitant diagnoses. History of cardiovascular disease was defined as any diagnosis of acute myocardial infarction, stroke, or angina at least one year before entry into the study cohort.

\section{Statistical analyses}

A proportional risk model was conducted and hazard ratios (HRs) with 95\% confidence intervals (CI) were estimated to evaluate the risk of death or cardiovascular disease in users of different categories of drug prescriptions. Current clopidogrel and PPI prescriptions were set as the reference. Patients who were diagnosed as having acute myocardial infarction at entry were analyzed as a subgroup and compared with patients diagnosed as having overall cardiovascular disease including acute myocardial infarction. Analyses were specified for patients who had a hospitalization for upper GI bleeding before or after the cardiovascular disease hospitalizations. The characteristics of patients for the diagnosis of upper GI bleeding were categorized into four groups based on a bleeding episode which happened before, during or after the study period. Group I contained patients who had a history of peptic ulcer bleeding before cohort entry. Group II contained patients who had a bleeding history and who bled again during the study period. Group III contained patients who had no history of bleeding but experienced a bleeding episode during the study period, and Group IV contained patients who did not bleed during but after the defined study period. Compared with the general population, all these patients are apt to have a higher risk of GI bleeding, therefore, reasonable subjects for analysis in a whole group [29,30]. Furthermore, we performed additional analysis for sub-groups. Since there are a limited number of patients in the third and fourth groups, we only did a sub-analysis for patients who had a history of upper GI bleeding (Groups I and II). All of the proportional models were adjusted for age $(<65,65-74,75-84, \geq 85)$, sex (male, female), history of cardiovascular disease (yes, no), history of bleeding (yes, no), and co-morbidity (0, 1, 2, 3 or more). To assess surveillance bias, additional analyses were conducted after 
excluding cases that died within 30 days after entry. SAS (the Statistical Analysis System, version 9.2, SAS Institute Inc., Cary, NC, USA) was used for all analyses. The study was approved by the Regional Ethical Review Board in Stockholm.

\section{Results}

\section{Study participants}

In total, 98725 cases of peptic ulcer bleeding were ascertained from the Swedish Patient Register. Among them, 2285 first cardiovascular disease events were included in the study. Table 1 shows the baseline characteristics of the study participants at the time of inclusion. Among the patients with cardiovascular disease, we also did a sub-group analysis for acute myocardial infarction (Tables 1 and 2). The cohorts were followed for the outcomes death and recurrence of cardiovascular disease. Of the 2285 cardiovascular disease patients, 1536 (67\%) were older than 75 years of age and $1269(56 \%)$ were men. There were 812 (36\%) current users of only PPIs, 165 (7\%)

Table 1 Characteristics of study participants diagnosed with cardiovascular disease

\begin{tabular}{|c|c|c|c|c|c|c|c|c|}
\hline \multirow[t]{3}{*}{ Characteristics } & \multicolumn{4}{|c|}{ Death } & \multicolumn{4}{|c|}{ Re-hospitalization for cardiovascular disease } \\
\hline & \multicolumn{2}{|c|}{ CVD* cohort } & \multicolumn{2}{|c|}{ AMI** cohort } & \multicolumn{2}{|c|}{ CVD* cohort } & \multicolumn{2}{|c|}{ AMI** cohort } \\
\hline & & \multicolumn{2}{|c|}{ Number (\%) } & \multicolumn{2}{|c|}{ Number (\%) } & \multicolumn{2}{|c|}{ Number (\%) } \\
\hline Total & 2219 & & 673 & & 2285 & & 695 & \\
\hline Men & 1227 & $55 \%$ & 365 & $54 \%$ & 1269 & $56 \%$ & 374 & $54 \%$ \\
\hline Women & 992 & $45 \%$ & 308 & $46 \%$ & 1016 & $44 \%$ & 321 & $46 \%$ \\
\hline \multicolumn{9}{|l|}{ Age group, years } \\
\hline$<65$ & 291 & $13 \%$ & 57 & $8 \%$ & 303 & $13 \%$ & 62 & $9 \%$ \\
\hline $65-75$ & 425 & $19 \%$ & 95 & $14 \%$ & 446 & $20 \%$ & 98 & $14 \%$ \\
\hline $75-85$ & 844 & $38 \%$ & 280 & $42 \%$ & 872 & $38 \%$ & 292 & $42 \%$ \\
\hline$>=85$ & 659 & $30 \%$ & 241 & $36 \%$ & 664 & $29 \%$ & 243 & $35 \%$ \\
\hline \multicolumn{9}{|l|}{ Upper gastrointestinal bleeding } \\
\hline I. Bleeding before entry & 1730 & $78 \%$ & 513 & $76 \%$ & 1773 & $78 \%$ & 527 & $76 \%$ \\
\hline II. Bleeding before entry and during the follow up & 49 & $2 \%$ & 22 & $3 \%$ & 44 & $2 \%$ & 20 & $3 \%$ \\
\hline III. New bleeding during the follow up period & 86 & $4 \%$ & 41 & $6 \%$ & 71 & $3 \%$ & 33 & $5 \%$ \\
\hline IV. Bleeding after endpoints & 354 & $16 \%$ & 97 & $14 \%$ & 397 & $17 \%$ & 115 & $17 \%$ \\
\hline \multicolumn{9}{|l|}{ Cardiovascular disease history } \\
\hline No & 1315 & $59 \%$ & 456 & $68 \%$ & 1361 & $60 \%$ & 475 & $68 \%$ \\
\hline Yes & 904 & $41 \%$ & 217 & $32 \%$ & 924 & $40 \%$ & 220 & $32 \%$ \\
\hline \multicolumn{9}{|l|}{ Comorbidities (number) } \\
\hline 0 & 1382 & $62 \%$ & 328 & $49 \%$ & 1426 & $62 \%$ & 340 & $49 \%$ \\
\hline 1 & 628 & $28 \%$ & 244 & $36 \%$ & 643 & $28 \%$ & 250 & $36 \%$ \\
\hline 2 & 173 & $8 \%$ & 81 & $12 \%$ & 178 & $8 \%$ & 85 & $12 \%$ \\
\hline$\geq 3$ & 36 & $2 \%$ & 20 & $3 \%$ & 38 & $2 \%$ & 20 & $3 \%$ \\
\hline \multicolumn{9}{|l|}{ Drug exposure } \\
\hline Current clopidogrel and PPIs§ & 309 & $14 \%$ & 95 & $14 \%$ & 403 & $18 \%$ & 116 & $17 \%$ \\
\hline No current PPIs or clopidogrel & 861 & $39 \%$ & 211 & $31 \%$ & 905 & $40 \%$ & 226 & $33 \%$ \\
\hline Current only PPIs & 847 & $38 \%$ & 316 & $47 \%$ & 812 & $36 \%$ & 308 & $44 \%$ \\
\hline Current only clopidogrel & 202 & $9 \%$ & 51 & $8 \%$ & 165 & $7 \%$ & 45 & $6 \%$ \\
\hline \multicolumn{9}{|l|}{ Patients with diagnosis of bleeding before entry } \\
\hline Current clopidogrel and PPIs & 252 & $14 \%$ & 78 & $15 \%$ & 244 & $13 \%$ & 77 & $14 \%$ \\
\hline No current PPIs or clopidogrel & 659 & $37 \%$ & 154 & $29 \%$ & 702 & $39 \%$ & 164 & $30 \%$ \\
\hline Current only PPIs & 714 & $40 \%$ & 265 & $50 \%$ & 713 & $39 \%$ & 266 & $49 \%$ \\
\hline Current only clopidogrel & 154 & $9 \%$ & 38 & $7 \%$ & 158 & $9 \%$ & 40 & $7 \%$ \\
\hline subtotal & 1779 & & 535 & & 1817 & & 547 & \\
\hline
\end{tabular}

*CVD cardiovascular disease; **AMI acute myocardial infarction; \$PPIs proton-pump inhibitors. 
Table 2 Risk of death or recurrent cardiovascular events in $\mathbf{9 0}$ days follow-up among cardiovascular disease patients

\begin{tabular}{|c|c|c|c|c|}
\hline \multirow[t]{3}{*}{ Drug exposures } & \multicolumn{2}{|c|}{ Cardiovascular disease cohort } & \multicolumn{2}{|c|}{ Acute myocardial infarction cohort } \\
\hline & Death & Cardiovascular disease & Death & Cardiovascular disease \\
\hline & $\S \mathrm{HR}(95 \% \mathrm{Cl})$ & $\S \mathrm{HR}(95 \% \mathrm{Cl})$ & $\S \mathrm{HR}(95 \% \mathrm{Cl})$ & $\S \mathrm{HR}(95 \% \mathrm{Cl})$ \\
\hline \multicolumn{5}{|l|}{ Total cohort } \\
\hline Current clopodogrel and PPI** (reference) & 1.00 & 1.00 & 1.00 & 1.00 \\
\hline No PPI and no clopidogrel & $2.36(1.39-4.00)$ & $1.54(1.05-2.24)$ & $3.13(1.47-6.68)$ & $1.77(0.92-3.41)$ \\
\hline Current only PPIs & $2.02(1.19-3.44)$ & $1.11(0.75-1.65)$ & $1.93(0.91-4.11)$ & $1.02(0.52-1.99)$ \\
\hline Current only clopidogrel & $1.14(0.53-2.45)$ & $1.80(1.15-2.83)$ & $1.88(0.70-5.03)$ & $1.88(0.85-4.08)$ \\
\hline \multicolumn{5}{|c|}{ Patients with diagnosis of bleeding before entry* } \\
\hline Current clopodogrel and PPI(reference) & 1.00 & 1.00 & 1.00 & 1.00 \\
\hline No PPI and no clopidogrel & $2.30(1.33-3.98)$ & $1.54(0.98-2.40)$ & $3.30(1.47-7.41)$ & $1.65(0.78-3.47)$ \\
\hline Current only PPI & $2.05(1.18-3.54)$ & $1.04(0.65-1.65)$ & $2.12(0.95-4.73)$ & $0.80(0.37-1.72)$ \\
\hline Current only clopidogrel & $1.25(0.57-2.72)$ & $1.84(1.07-3.16)$ & $2.26(0.82-6.26)$ & $1.78(0.70-4.57)$ \\
\hline
\end{tabular}

${ }^{*}$ cohort members had history of upper gastrointestinal bleeding before entry into the cohorts. Results for patients who had any other hospitalizations for upper gastrointestinal bleeding were not shown due to the small number of cases.

**PPIs proton-pump inhibitors.

$\S H R$ harzard ratio; $C l$ confidence interval. All of the proportional models were adjusted for age $(<65,65-74,75-84, \geq 85)$, sex (male, female), history of cardiovascular diseases (yes, no), history of bleeding (yes, no), and co-morbidity $(0,1,2,3$ or more).

current users of only clopidogrel, and 403 (18\%) current users of concomitant prescriptions of PPIs and clopidogrel. In patients who only used one type of PPI, there were 878 omeprazole users, 162 esomeprazole users, 96 lansoprazole, 95 pantoprazole and 5 rabeprazole users. Among all participants, 245 (11\%) died within the 90-day followup, 158 (7\%) suffered ischemic stroke and 8 (0.3\%) hemorrhagic stroke, while among 1817 (80\%) patients with a diagnosis of upper GI bleeding before first entry into the cardiovascular disease cohort, 225 (13\%) died within 90 days after discharge.

\section{Hazard ratios for different drug exposures in the cardiovascular disease cohort}

The HR for risk of death within 90 days of follow-up was 2.02 (95\% CI 1.19-3.44) for current users of only PPIs, 1.14 (95\% CI 0.53-2.45) for current users of only clopidogrel, and 2.36 (95\% CI 1.39-4.00) among patients with no PPI or clopidogrel prescription, compared with patients using PPIs and clopidogrel concomitantly (Table 2). Regarding the risk of recurrent cardiovascular disease, the corresponding HRs were: 1.11 (95\% CI 0.751.65), 1.80 (95\% CI 1.15-2.83), and 1.54 (95\% CI 1.05$2.24)$, respectively.

\section{Hazard ratios for different drug exposures in the acute myocardial infarction cohort}

In the acute myocardial infarction cohort, the HR for risk of death was 1.93 (95\% 0.91-4.11) for current users of only PPIs, 1.88 (95\% 0.70-5.03) for current users of only clopidogrel, and 3.13 (95\% CI 1.47-6.68) for patients with no PPI or clopidogrel prescriptions. All the
HRs for the risk of recurrent cardiovascular disease after acute myocardial infarction are not statistically different when compared to concomitant use of PPIs and clopidogrel.

\section{Patients with a diagnosis of upper GI bleeding before entry}

Patients with any upper GI bleeding diagnosis before entry into the study were analyzed separately. The results were consistent with the main analyses (Table 2). An elevated risk of death (HR 2.05, 95\% 1.18-3.54) was detected for current only PPIs, and an increased risk of recurrent cardiovascular disease (HR 1.84, 95\% CI 1.073.16) was found for current use of only clopidogrel, compared with concomitant use of PPIs and clopidogrel. Restricting the cohort to those who had experienced a bleeding within one year before entry rendered similar results (data not shown).

\section{Discussion and conclusions}

This study reveals no evidence of an increased risk of death or recurrence of cardiovascular disease among concomitant users of clopidogrel and PPIs in a population with a high risk of upper GI bleeding. Use of clopidogrel or PPIs alone seems to increase the risk of mortality and recurrent cardiovascular disease compared with concomitant use of these drugs.

Strengths of the study include the large sample size and the data collection from registers with complete nationwide coverage of the drug exposures and outcomes, i.e., recurrent cardiovascular disease and death. The nationwide register-based design counteracts selection and 
recall bias. Moreover, confounding was reduced by excluding patients with any recorded prescription of aspirin. There are, however, also several weaknesses. Filled prescriptions of PPIs and clopidogrel were regarded as the exposure, but there was no information on whether the patients had actually taken their medications. Also, PPI sub-types could not be analyzed separately due to the limited number, although the safety of pantoprazole has been specifically targeted in some studies [31]. More studies with a large sample size for possibly separating the analysis of PPI subtypes are warranted. In addition, it was not possible to entirely distinguish patients with a filled prescription after hospital admission from patients who still had drugs left from prescriptions filled before the index admission. Furthermore, we had no data on some important risk factors at baseline, such as tobacco smoking and alcohol consumption, which may bias the results [32]. We were, however, able to control for cardiovascular history and other co-morbidity as registered on hospital admission. Finally, confounding by indication could not be avoided completely in this observational study. Reasons for patients lacking any prescriptions might indicate that some completely recovered or that they might have had such severe symptoms that their physicians decided not to use any medication. These two opposite statuses of patients might make the confounding by indication less influential. The reason why some patients had only prescriptions of clopidogrel or only PPIs might be due to the recent reports of the increased risk of concomitant use of these two drugs rather than any specific disease indications. On the other hand, the consistently increased risk of recurrence of cardiovascular disease in clopidogrel only patients compared with the concomitant users may indicate the competing risk of death in this group.

Whether concomitant prescriptions of clopidogrel PPIs are associated with an increased recurrence of cardiovascular events is controversial [33]. Some studies have indicated a concern that the interaction between clopidogrel and PPIs could impair the treatment effect of clopidogrel $[10-14,16]$, but others have not found any association. Instead, an independent cardiovascular risk by PPIs alone has been detected in a few studies. Several relevant metaanalyses have been published since 2010. Hulot and his coworkers initiated a meta-analysis in 2009 focusing on clopidogrel-treated patients with cytochrome P450 2C19*2 loss-of-function allele or the co-administration of PPIs. The results displayed an increased risk of major adverse cardiovascular events in the co-administration of clopidogrel and PPIs [34]. During the same year, the study by Kwok et al. showed that propensity-matched or randomized trial participants had no associated cardiovascular risk with PPIs, whereas other observational studies generally showed a significant association [35]. The same team published an updated study in 2012 with a focus on the potential risk with individual PPIs. They found an elevated risk of PPI therapy alone is associated with an adverse cardiovascular risk. They also admitted that major adverse cardiovascular events were mostly limited by the moderate to substantial heterogeneity of the studies included for meta-analysis. The high possibility of confounding and bias was indicated [31]. Siller-Matula and his colleagues published another metaanalysis in 2010. Their results indicated that concomitant PPI use might be associated with an increased risk of cardiovascular events but does not influence the risk of death. Articles included in these meta-analyses were not completely the same due to different inclusion criteria and time of publication. They further confirmed the presence of significant heterogeneity which might indicate that the evidence is biased, confounded, or inconsistent [36]. The clinical validity or relevance of the hypothesized PPI-clopidogrel interaction, thus, remains questionable.

The present study indicates that the co-administration of clopidogrel and PPIs results in a better effect regarding the prevention of death in patients with a high risk of GI bleeding. The current findings are consistent with some previous studies [17-20,37-40]. For example, a cohort study in the US and Canada which included 18565 patients with acute coronary syndrome undergoing percutaneous coronary intervention (PCI) found no conclusive evidence of a clopidogrel-PPI interaction, even though there was a slightly increased risk of hospitalization for myocardial infarction. A study from Austria included 300 patients with coronary artery disease who had PCI. The platelet reactivity index was measured in patients with and without PPIs, and no interaction was found between clopidogrel and pantoprazole or esomeprazole [17]. One big cohort study from Denmark found that the apparent association between recurrent myocardial infarction and the use of PPIs with clopidogrel is affected by confounding by indication. The association is not present when confounding is addressed by design [41]. Although indications of reduced antiplatelet activity have been found in vivo in the case of PPI administration in clopidogrel users, the interaction between antiplatelet agents and PPIs at the enzymatic level does not seem to result in worse clinical outcomes.

In summary, recent studies have shown conflicting and inconsistent data regarding the adverse interaction of clopidogrel and PPIs. Together with our study, we think clinicians should focus on the potential harm from ulcers or hemorrhage before deciding to omit PPIs in patients taking clopidogrel. In selected patients at highrisk of GI bleeding, clinicians should in fact be very cautious and cannot overlook the life-threatening risk that bleedings represent. 


\section{Competing interests}

All authors have no competing interests to declare: no support from any organization for the submitted work; no financial relationships with any organizations that might have an interest in the submitted work in the previous three years and no other relationships or activities that could appear to have influenced the submitted work.

\section{Authors' contributions}

QW participated in the study design, carried out the statistical analysis and drafted the manuscript. RL collected the data, contributed to data arrangement, data analysis, and interpretation of results and helped to draft the manuscript; $J$ participated in the study design, contributed to interpretation of the results and drafted the manuscript; LY conceived of the study, contributed to the acquisition of the data, participated in the study design and helped to draft the manuscript. All authors read and approved the final manuscript.

\section{Acknowledgements}

We acknowledge financial support from the Swedish Research Council (SIMSAM), the Swedish Medical Society and the Karolinska foundation. None of these funding bodies had any role in any process of the current study.

\section{Author details}

'Department of Molecular Medicine and Surgery, Karolinska Institutet, SE-171 76 Stockholm, Sweden. ${ }^{2}$ Unit of Epidemiology, Institute of Environmental Medicine, Karolinska Institutet, Stockholm, Sweden. ${ }^{3}$ Division of Cancer Studies, King's College London, London, United Kingdom. ${ }^{4}$ Department of Epidemiology and Biostatistics, Imperial College London, London, United Kingdom.

Received: 2 August 2013 Accepted: 25 March 2014

Published: 15 April 2014

\section{References}

1. Terpening C: Clopidogrel: a pharmacogenomic perspective on its use in coronary artery disease. Clin Med Insights Cardiol 2010, 4:117-128. PubMed PMID: 21151850. Pubmed Central PMCID: 2998935. Epub 2010/12/15. eng.

2. Tran H, Anand SS: Oral antiplatelet therapy in cerebrovascular disease, coronary artery disease, and peripheral arterial disease. JAMA 2004, 292(15):1867-1874. PubMed PMID: 15494585. Epub 2004/10/21. eng.

3. Rogowski W, Burch J, Palmer S, Craigs C, Golder S, Woolacott N: The effect of different treatment durations of clopidogrel in patients with non-STsegment elevation acute coronary syndromes: a systematic review and value of information analysis. Health Technol Assess 2009, 13(31):1-77. iii-iv, ix-xi, PubMed PMID: 19573471. Epub 2009/07/04. eng.

4. Jackowski L, Stocks N, Rowett D: Reducing the risk of adverse thrombotic events - The role of aspirin and clopidogrel. Aust Fam Physician 2008, 37(9):721-723. 5-6. PubMed PMID: 18797530. Epub 2008/09/18. eng.

5. Boparai V, Rajagopalan J, Triadafilopoulos G: Guide to the use of proton pump inhibitors in adult patients. Drugs 2008, 68(7):925-947. PubMed PMID: 18457460. Epub 2008/05/07. eng.

6. Madanick RD: Proton pump inhibitor side effects and drug interactions: much ado about nothing? Cleve Clin J Med 2011, 78(1):39-49. PubMed PMID: 21199906. Epub 2011/01/05. eng.

7. Furuta T: Risk and benefit of proton pump inhibitor for patients undergoing anti-platelet therapy including clopidogrel. Intern Med 2009, 48(21):1847-1848. PubMed PMID: 19881232. Epub 2009/11/03. eng.

8. Moayyedi P, Sadowski DC: Proton pump inhibitors and clopidogrel hazardous drug interaction or hazardous interpretation of data? Can $J$ Gastroenterol 2009, 23(4):251-252. PubMed PMID: 19373416. Pubmed Central PMCID: 2711671. Epub 2009/04/18. eng.

9. Barrison AF, Jarboe LA, Weinberg BM, Nimmagadda $K$, Sullivan LM, Wolfe MM: Patterns of proton pump inhibitor use in clinical practice. Am J Med Genet 2001, 111(6):469-473. PubMed PMID: 11690573.

10. Huang CC, Chen YC, Leu HB, Chen TJ, Lin SJ, Chan WL, Chen JW: Risk of adverse outcomes in Taiwan associated with concomitant use of clopidogrel and proton pump inhibitors in patients who received percutaneous coronary intervention. Am J Cardiol 2010, 105(12):1705-1709. PubMed PMID: 20538118. Epub 2010/06/12. eng.
11. Gupta E, Bansal D, Sotos J, Olden K: Risk of adverse clinical outcomes with concomitant use of clopidogrel and proton pump inhibitors following percutaneous coronary intervention. Dig Dis Sci 2009, 55(7):1964-1968. PubMed PMID: 19731021. Epub 2009/09/05. eng.

12. Ho PM, Maddox TM, Wang L, Fihn SD, Jesse RL, Peterson ED, Peterson ED, Rumsfeld JS: Risk of adverse outcomes associated with concomitant use of clopidogrel and proton pump inhibitors following acute coronary syndrome. JAMA 2009, 301(9):937-944. PubMed PMID: 19258584. Epub 2009/03/05. eng.

13. Juurlink DN, Gomes T, Ko DT, Szmitko PE, Austin PC, Tu JV, Henry DA, Kopp A, Mamdami MM: A population-based study of the drug interaction between proton pump inhibitors and clopidogrel. CMAJ 2009, 180(7):713-718. PubMed PMID: 19176635. Pubmed Central PMCID: 2659819. Epub 2009/01/30. eng

14. Stockl KM, Le L, Zakharyan A, Harada AS, Solow BK, Addiego JE, Ramsey S: Risk of rehospitalization for patients using clopidogrel with a proton pump inhibitor. Arch Intern Med 2010, 170(8):704-710. PubMed PMID: 20421557. Epub 2010/04/28. eng.

15. Gilard M, Arnaud B, Cornily JC, Le Gal G, Lacut K, Le Calvez G, Mansourati J, Mottier D, Abgrall JF, Boschat J: Influence of omeprazole on the antiplatelet action of clopidogrel associated with aspirin: the randomized, double-blind OCLA (Omeprazole CLopidogrel Aspirin) study. J Am Coll Cardiol 2008, 51(3):256-260. PubMed PMID: 18206732. Epub 2008/01/22. eng

16. Pezalla E, Day D, Pulliadath I: Initial assessment of clinical impact of a drug interaction between clopidogrel and proton pump inhibitors. J Am Coll Cardiol 2008, 52(12):1038-1039. author reply 9. PubMed PMID: 18786491. Epub 2008/09/13. eng.

17. Bhatt DL, Cryer BL, Contant CF, Cohen M, Lanas A, Schnitzer TJ, Shook TL, Lapuerta P, Goldsmith MA, Laine L, Scirica BM, Murphy SA, Cannon CP, COGENT Investigators: Clopidogrel with or without omeprazole in coronary artery disease. N Engl J Med 2010, 363(20):1909-1917. PubMed PMID: 20925534. Epub 2010/10/12. Eng.

18. O'Donoghue ML, Braunwald E, Antman EM, Murphy SA, Bates ER, Rozenman Y, Rozenman Y, Michelson AD, Hautvast RW, Ver Lee PN, Close SL, Shen L, Mega JL, Sabatine MS, Wiviott SD: Pharmacodynamic effect and clinical efficacy of clopidogrel and prasugrel with or without a proton-pump inhibitor: an analysis of two randomised trials. Lancet 2009, 374(9694):PubMed PMID: 19726078-PubMed PMID: 19726997. PubMed PMID: 19726078

19. Rassen JA, Choudhry NK, Avorn J, Schneeweiss S: Cardiovascular outcomes and mortality in patients using clopidogrel with proton pump inhibitors after percutaneous coronary intervention or acute coronary syndrome. Circulation 2009, 120(23):2322-2329. PubMed PMID: 19933932. Pubmed Central PMCID: 2818789. Epub 2009/11/26. eng.

20. Ray WA, Murray KT, Griffin MR, Chung CP, Smalley WE, Hall K, Hall K, Daugherty JR, Kaltenbach LA, Stein CM: Outcomes with concurrent use of clopidogrel and proton-pump inhibitors: a cohort study. Ann Intern Med 2010, 152(6):337-345. PubMed PMID: 20231564. Pubmed Central PMCID: 3176584 .

21. Administration. UFaD: Information for healthcare professionals: update to the labeling of clopidogrel bisulfate (marketed as Plavix) to alert healthcare professionals about a drug interaction with omeprazole (marketed as Prilosec and Prilosec OTC). U.S. Department of Health and Human Services. 11/17/2009. http://www.fda.gov/Drugs/DrugSafety/ PostmarketDrugSafetyInformationforPatientsandProviders/ DrugSafetylnformationforHeathcareProfessionals/ucm 190787.htm.

22. Juhasz M, Herszenyi L, Tulassay Z: Current standings of the proton pump inhibitor and clopidogrel co-therapy: review on an evolving field with the eyes of the gastroenterologist. Digestion 2010, 81(1):10-15. PubMed PMID: 20029203. Epub 2009/12/24. eng.

23. Tsai YW, Wen YW, Huang WF, Chen PF, Kuo KN, Hsiao FY: Cardiovascular and gastrointestinal events of three antiplatelet therapies: clopidogrel, clopidogrel plus proton-pump inhibitors, and aspirin plus proton-pump inhibitors in patients with previous gastrointestinal bleeding. J Gastroenterol 2011, 46(1):39-45. PubMed PMID: 20811753.

24. Hsu PI, Lai KH, Liu CP: Esomeprazole with clopidogrel reduces peptic ulcer recurrence, compared with clopidogrel alone, in patients with atherosclerosis. Gastroenterology 2011, 140(3):791-798. PubMed PMID: 21144850 
25. Gaglia MA Jr, Torguson R, Hanna N, Gonzalez MA, Collins SD, Syed Al, Syed Al, Ben-Dor I, Maluenda G, Delhaye C, Wakabayashi K, Xue Z, Suddath WO, Kent KM, Satler LF, Pichard AD, Waksman R: Relation of proton pump inhibitor use after percutaneous coronary intervention with drug-eluting stents to outcomes. Am J Cardiol 2010, 105(6):833-888. PubMed PMID: 20211327.

26. Hsiao FY, Mullins CD, Wen YW, Huang WF, Chen PF, Tsai YW: Relationship between cardiovascular outcomes and proton pump inhibitor use in patients receiving dual antiplatelet therapy after acute coronary syndrome. Pharmacoepidemiol Drug Saf 2011, 20(10):1043-1049. PubMed PMID: 21823195

27. Ahsberg K, Hoglund P, Stael von Holstein C: Mortality from peptic ulcer bleeding: the impact of comorbidity and the use of drugs that promote bleeding. Aliment Pharmacol Therapeut Symp 2010, 32(6):801-810. PubMed PMID: 20653635

28. Jepsen P, Vilstrup H, Lash TL: Development and Validation of a Comorbidity Scoring System for Patients With Cirrhosis. Gastroenterology 2014, 146(1):147-156. quiz e15-6. doi: 10.1053/j.gastro.2013.09.019. Epub 2013 Sep 18. PubMed PMID: 24055278.

29. Bratanic A, Puljiz Z, Ljubicicz N, Caric T, Jelicic I, Puljiz M, Puljiz M, Perko Z: Predictive factors of rebleeding and mortality following endoscopic hemostasis in bleeding peptic ulcers. Hepatogastroenterology 2013, 60 (121):112-117. PubMed PMID: 22709912

30. Lau JY, Barkun A, Fan DM, Kuipers EJ, Yang YS, Chan FK: Challenges in the management of acute peptic ulcer bleeding. Lancet 2013, 381 (9882):2033-2043. PubMed PMID: 23746903.

31. Kwok CS, Jeevanantham V, Dawn B, Loke YK: No consistent evidence of differential cardiovascular risk amongst proton-pump inhibitors when used with clopidogrel: meta-analysis. Int J Cardiol 2013, 167(3):965-974. PubMed PMID: 22464478

32. Focks JJ, Brouwer MA, van Oijen MG, Lanas A, Bhatt DL, Verheugt FW: Concomitant use of clopidogrel and proton pump inhibitors: impact on platelet function and clinical outcome- a systematic review. Heart 2013, 99(8):520-527. PubMed PMID: 22851683.

33. Kwok CS, Nijjar RS, Loke YK: Effects of proton pump inhibitors on adverse gastrointestinal events in patients receiving clopidogrel: systematic review and meta-analysis. Drug Saf 2010, 34(1):47-57. PubMed PMID: 21047145. Epub 2010/11/05. eng.

34. Hulot JS, Collet JP, Silvain J, Pena A, Bellemain-Appaix A, Barthelemy O Cayla G, Beygui F, Montalescot G: Cardiovascular risk in clopidogreltreated patients according to cytochrome P450 2C19*2 loss-offunction allele or proton pump inhibitor coadministration: a systematic meta-analysis. J Am Coll Cardiol 2010, 56(2):134-143. PubMed PMID: 20620727.

35. Kwok CS, Loke YK: Meta-analysis: the effects of proton pump inhibitor on cardiovascular events and mortality in patients receiving clopidogrel. Aliment Pharmacol Therapeut Symp 2010, 31(8):810-823. PubMed PMID: 20102352

36. Siller-Matula JM, Jilma B, Schror K, Christ G, Huber K: Effect of proton pump inhibitors on clinical outcome in patients treated with clopidogrel: a systematic review and meta-analysis. J Thromb Haemostasis 2010, 8(12):2624-2641. PubMed PMID: 20831618.

37. Siller-Matula JM, Spiel AO, Lang IM, Kreiner G, Christ G, Christ G, Jilma B: Effects of pantoprazole and esomeprazole on platelet inhibition by clopidogrel. Am Heart J 2009, 157(1):148 e1-5. PubMed PMID: 19081411. Epub 2008/12/17. eng.

38. Bhurke SM, Martin BC, Li C, Franks AM, Bursac Z, Said Q: Effect of the clopidogrel-proton pump inhibitor drug interaction on adverse cardiovascular events in patients with acute coronary syndrome. Pharmacotherapy 2012, 32(9):809-818. PubMed PMID: 22744772. Pubmed Central PMCID: 3531962

39. Leontiadis Gl, Howden CW: PPI co-therapy did not adversely affect outcomes in clopidogrel users. Aliment Pharmacol Therapeut Symp 2012, 35(2):313-314. PubMed PMID: 22172084

40. Schmidt M, Johansen MB, Robertson DJ, Maeng M, Kaltoft A, Jensen LO, Tilsted HH, Bøtker HE, Sørensen HT, Baron JA: Concomitant use of clopidogrel and proton pump inhibitors is not associated with major adverse cardiovascular events following coronary stent implantation.
Alimentary pharmacology \& therapeutics 2012, 35(1):165-174. PubMed PMID: 22050009.

41. Valkhoff VE, t Jong GW, Van Soest EM, Kuipers EJ, Sturkenboom MC: Risk of recurrent myocardial infarction with the concomitant use of clopidogrel and proton pump inhibitors. Aliment Pharmacol Therapeut Symp 2011, 33(1):77-88. PubMed PMID: 21083580

doi:10.1186/2050-6511-15-22

Cite this article as: Wang et al.: Prognosis of concomitant users of clopidogrel and proton-pump inhibitors in a high-risk population for upper gastrointestinal bleeding. BMC Pharmacology and Toxicology 2014 15:22

\section{Submit your next manuscript to BioMed Central and take full advantage of:}

- Convenient online submission

- Thorough peer review

- No space constraints or color figure charges

- Immediate publication on acceptance

- Inclusion in PubMed, CAS, Scopus and Google Scholar

- Research which is freely available for redistribution

Submit your manuscript at www.biomedcentral.com/submit
C) BioMed Central 